\title{
Electronic nose based on piezoelectric quartz crystal array sensors for the discrimination of different types of coffee beans
}

\author{
Geminesse S. Sianghio, ${ }^{1,2}$ Vernalyn R. Abarintos ${ }^{2}$, and Dharmatov Rahula B. Albano ${ }^{1,2}$ \\ ${ }^{1}$ Research Center for the Natural and Applied Sciences \\ ${ }^{2}$ The Graduate School \\ University of Santo Tomas, Manila Philippines 1015 \\ geminesse.sianghio.gs@ust.edu.ph
}

\begin{abstract}
:
An array of piezoelectric quartz crystal (PQC) based on organic polymers was assembled for the differentiation of types of coffees. Each PQC sensors were coated with polystyrene, polyvinyl chloride, ethyl cellulose, polyethylene glycol, polycyanoacrylate, and polyvinyl acetate. The frequency shift of the sensors were measured and observed to change when exposed to the headspace of coffee beans. The sensor response was rapid and exhibited good reversibility and reproducibility. Different signals were obtained for each coffee bean sample and pattern recognition techniques were employed for the analysis of the data. The developed E-nose system was able to discriminate kopi luwak (Civet coffee), Philippine baraco (liberica), excelsa, robusta and arabica.
\end{abstract}

Key words: piezoelectric quartz crystal, electronic nose, coffee

\section{Measurement Procedure}

The crystals were coated with the sensing polymer using the drop-coating method. Each coffee bean samples had quintuplicates. The headspace VOCs generated over the sample were exposed to the sensor. The difference between the reading that is obtained from the blank and of that which is obtained from the sample were taken as the sensor response. The change in resonant frequency $(\Delta \mathrm{F})$ is related to the change in the mass loading that is described by the Sauerbrey equation[1]. The e-nose fabricated is shown in Figure 1, six crystals coated with different polymers were closely aligned together, each sensor giving independent response.

$$
\Delta \mathrm{F}=-2.26 \times 10^{6} \mathrm{~F}^{2}\left(\Delta \mathrm{M}_{\mathrm{s}} / \mathrm{A}\right)
$$

where:

$\Delta \mathrm{F} \quad$ change in frequency due to coating

$\Delta \mathrm{M}_{\mathrm{s}} \quad$ mass of film of any substance coated on quartz

A surface area of the quartz plate

$\mathrm{F}$ fundamental frequency of the crystal

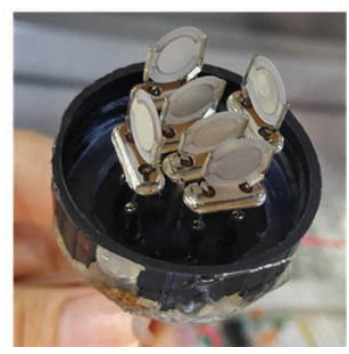

Figure 1: PQC array sensor

\section{Experimental Results}

Several important parameters for the sensor preparation, sample preparation and measurement procedures were investigated and optimized. The optimized weight of whole coffee bean sample was $3.0 \mathrm{~g}$. Both sides of the quartz crystal electrode were coated with $1 \mathrm{uL}$ of the polymer. The polymers PEG, PS, EC and polycyanoacrylate show that at 1.0 $\mathrm{mg} / \mathrm{mL}$ the sensor gave the best response, while for PEVA and PVC the concentration of $0.01 \mathrm{mg} / \mathrm{mL}$ was better [2]. The typical response of the e-nose is shown on Figure 2, which also shows the immediate response of the sensor to the VOCs and the repeatability of the sensor. 


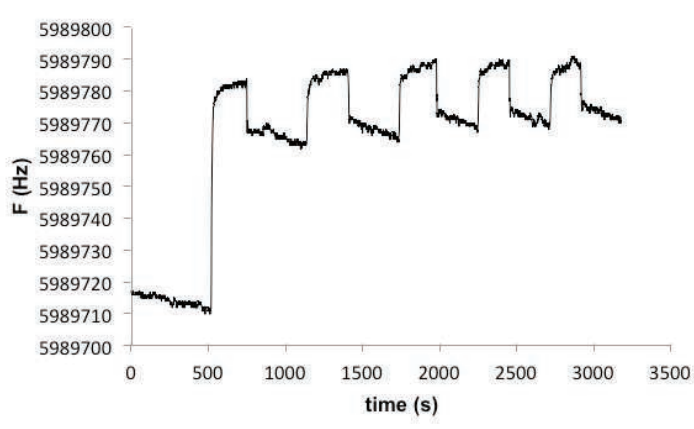

Figure 2. Typical PQC E-nose piezogram of Robusta using polyCA coated $P Q C(1 \mathrm{mg} / \mathrm{mL}$ polyCA, $1 \mu \mathrm{L}$ polyCA, $3 g$ whole bean Robusta sample).

In Figure 3, the 2D PCA plot and cluster analysis of the six sensors response is shown for the five types of coffee. There were a total of 5 clusters that were present in the 2D plot, the 2 sub clusters for the excelsa and arabica clusters were taken as one major cluster. By observing the 2D plot, it can be deduced that the Robusta sample was the only variety that was effectively discriminated, while the 4 other types clustered with the other types that have the same properties such as baraco and kopi luwak, excelsa and arabica.

\section{References}

[1] G. Sauerbrey, Verwendung von Schwingquarzen zur Wägung dünner Schichten und zur Mikrowägung, Zeitschrift Für Phys. $155 \quad$ (1959) 206-222. doi:10.1007/BF01337937.

[2] E. Ongo, M. Falasconi, G. Sberveglieri, A. Antonelli, G. Montevecchi, V. Sberveglieri, I. Concina, F.S. lii, Chemometric discrimination of philippine civet coffee using electronic nose and gas chromatography mass spectrometry, Procedia Eng. 47 (2012) 977980. doi:10.1016/j.proeng.2012.09.310.

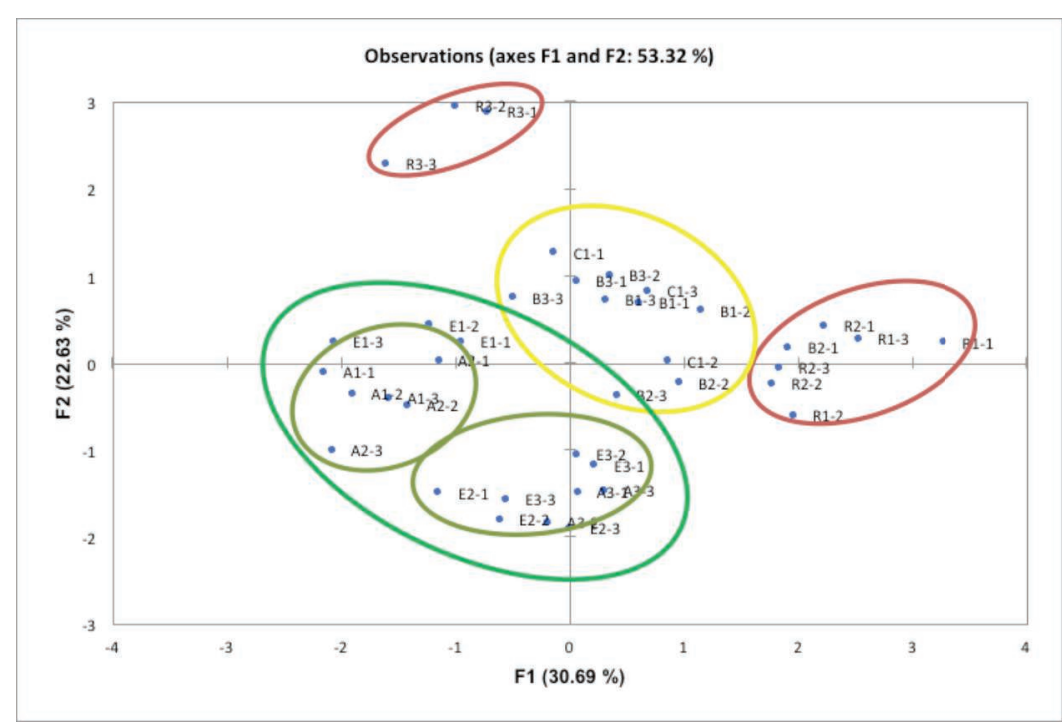

Figure 3. 2D PCA plot of the five types of coffee (Philippine baraco, kopi luwak, excelsa, arabica and robusta).

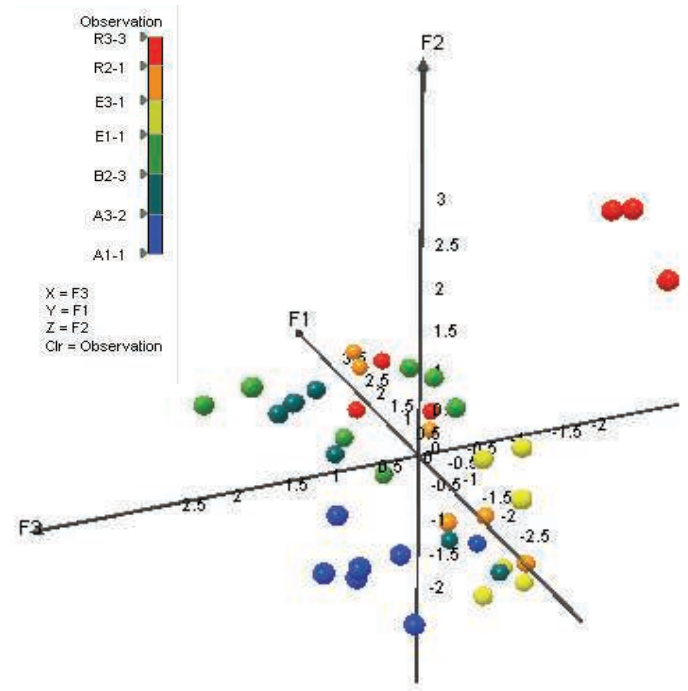

Figure 4. 3D PCA Plot showing the clustering of the different types of coffee. 